\section{Masked Facies}

Anna DePold Hohler ${ }^{1}$ and Marcus Ponce de Leon $^{2}$

${ }^{1}$ Boston University Medical Center, Boston, MA, USA

${ }^{2}$ William Beaumont Army Medical Center, El

Paso, TX, USA

\section{Synonyms}

Facial bradykinesia; Hypomimia; Poker face

\section{Definition}

A decrease in facial animation that may be seen in Parkinson's disease or with parkinsonism. It is felt to be a manifestation of bradykinesia in the face.

\section{Current Knowledge}

Facial movements are present, but a decrease in their frequency and amplitude gives the appearance of the patient wearing a mask. Patients may appear to family members as serious or depressed. Patients with masked facies may complain of dry eyes due to decreased eye blinking and of drooling from an associated decrease in the frequency of swallowing.

\section{Cross-References}

Parkinsonism

\section{References and Readings}

Pahwa, R., \& Lyons, K. E. (2007). Handbook of Parkinson's disease (4th ed.). New York: Informa Healthcare USA. 